\title{
Tensile Properties of Epoxy Grout Incorporating Graphene Nanoplatelets for Pipeline Repair
}

\author{
Nurfarahin Zainal ${ }^{1}$, Hanis Hazirah Arifin ${ }^{1}$, Libriati Zardasti ${ }^{1}$, Nordin Yahaya ${ }^{1}$, Kar Sing \\ Lim $^{2}$, Jian Wey Lai ${ }^{3}$, and Norhazilan Md Noor ${ }^{1, *}$ \\ ${ }^{1}$ Faculty of Civil Engineering, Universiti Teknologi Malaysia, UTM Skudai, Johor 81310, Malaysia \\ ${ }^{2}$ Faculty of Civil Engineering and Earth Resources, Universiti Malaysia Pahang, Gambang, 26300 \\ Kuantan, Pahang, Malaysia
}

${ }^{3}$ Orbiting Scientific \& Teknologi Sdn Bhd, Sri Petaling, 57000 Kuala Lumpur, Malaysia

\begin{abstract}
In oil and gas industry, fibre-reinforced polymer (FRP) composite are widely used to repair pipeline subjected to external metal loss. This repair technique can be done by incorporating epoxy grout as infill material to smoothen the defect on pipeline surface and later wrapped with a composite wrap to restore the strength of the pipe. This paper attempts to investigate the behaviour of an epoxy grout with $0.5 \mathrm{wt} \%$ graphene nanoplatelets ( $\mathrm{GnPs}$ ) under tensile loading according to the ASTM D638. GnPs were dispersed through the sonication method followed by calendering process to ensure an optimum enhancement in the properties of polymer matrix can be achieved. The results show positive improvement in terms of strength and Young's modulus of tested grout with the inclusion of GnPs. It shows that the presence of low concentration of GnPs as an additive has a significant reinforcement effect by improving tensile properties of epoxy grout up to $14 \%$ as compared to control sample.
\end{abstract}

\section{Introduction}

Steel pipelines are the most convenient and important tools in transferring oil and gas for onshore and offshore. However, due to the harsh environment, the integrity of this pipeline will deteriorate over time. Corrosion is one of the major problems in the pipeline system that will result in metal loss either internally or externally which may eventually lead to failure [1]. Recently, applications of Fibre Reinforced Polymer (FRP) composites has emerged as an alternative repair system for structural reinforcement, especially for oil and gas industry. Compared to traditional repair technique, FRP repair technique offer numerous advantages such as cost and time effective, the repairs can be done without interrupting the pipeline operation and safer as the welding and cutting processes are not involved thereby preventing the potential of hazards such as explosion risks [2]-[4]. Together with other advantages such as high strength, stiffness, and corrosion resistance, FRP has become a promising candidate for rehabilitation of the corroded steel pipeline structures [5], [6]. Apart from replacing the whole segment, FRP composite can be used to minimize the cost of pipeline repair with the

\footnotetext{
${ }^{*}$ Corresponding author: nurfarahin22@live.utm.my
} 
capability of recovering its strength effectively. This practices must be accompanied with epoxy grout which is used to flatten the damaged surface of steel pipe. A composite wrap will then be used to wrap around the repair segment of damaged pipe with adhesive applications on each layer as a bonding agent [7].

Nowadays, the future trend will likely focus on optimizing the design of composite repair system and there are intense efforts in reducing or eliminating the use of composite wrap in the pipeline repair system for cost reduction sake. This aforementioned goal can be achieved by strengthening the infill material of composite repair system used to smoothen the metal loss surface (pit) since the grout performance can give a great impact on the effectiveness of the pipeline repair system [4], [8]. The efforts to enhance the infill material properties have been started recently by adding graphene nanomaterial into the epoxy matrix [9], [10]. These efforts provide a glimpse of future research trends since the nanomaterial has great potential to enhance the infill material and due to that reason, further investigation of this matter is vitally required. In attaining the ideal improvement of the infill material properties, several factors should be considered, such as (a) ideal nanomaterial dispersion in the polymeric matrix, and (b) optimum nanomaterial content required to successfully enhance the material properties. In this study, graphene nanomaterial was selected as an additive in epoxy grout due to its superior properties. It is known as the most suitable reinforcing agents for polymers and they have been widely used to improve the mechanical, thermal and electrical properties of epoxy polymers [11], [12]. These outstanding performance could be attributed to its large specific area and packed carbon atom aligned in the hexagonal structure [13]. In the pressurized pipeline, the most dominant and critical stress is hoop stress and is commonly associated with tensile properties. Therefore, high tensile modulus and strength are required so that the pipe is capable to withstand the stress and sustained the pipe from fail. In the current work, graphene nanoplatelets were introduced into a commercially available epoxy grout. The effects of graphene on the tensile properties of epoxy grout were investigated as stand-alone material to observe their capability as infill materials. Hence, this paper will study the potential of graphene nanomaterial in improving the tensile properties of infill material to be used in pipeline composite repair system.

\section{Experimental work}

\subsection{Materials}

In this research, commercially available epoxy grout was selected to be used based on a combination of high viscosity resins and low viscosity hardener. Commonly, this epoxy grout is used for grouting and filling in a construction application. The modification of the existing grout was conducted and nanomaterial; graphene nanoplatelets; was added as an additive, later this grout was denoted as modified epoxy grout. The graphene nanoplatelets (GnPs) with an appearance of black/ grey powder have an average thickness of approximately 0.68 $3.41 \mathrm{~nm}$ while its particle diameter is $1-4 \mu \mathrm{m}$ with $>99.5 \mathrm{wt} \%$ carbon content.

\subsection{Graphene nanoplatelets dispersion}

A weighted amount of as-received GnPs was prepared at the desired concentrations. First, a sonication process was applied using Hielscher ultrasound sonicator in an acetone solution for 45 minutes. Then, it was left to evaporate for 24 hours at room temperature. Subsequently, GnPs and resin were mixed together and manually stir until the GnPs was completely dissolved. The second dispersion process was conducted using a three roll mill machine 
(EXAKT 80E Advanced Technologies $\mathrm{GmbH}$ ) to achieve homogeneous dispersion as shown in Figure 1.

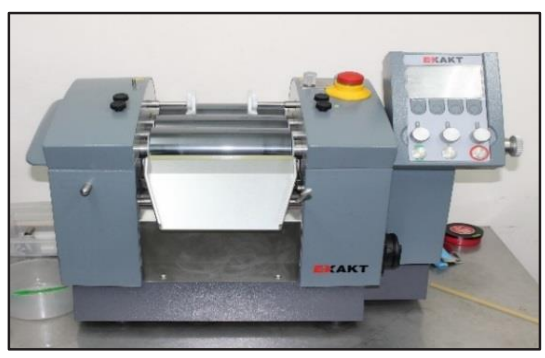

(a) Three roll mill machine

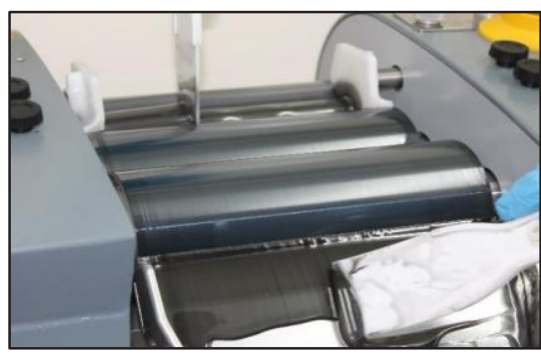

(b) Dispersion of graphene

Fig. 1. Dispersion process using three-roll mill machine.

The calendering process was applied for four consecutive times for each batch and the time required for each mill-rolling cycle was approximately 10 minutes. Graphene was dispersed in the resin by enormous shear forces resulting from the rollers turning at a speed ratio of 9:3:1. During the process, the rotational speed applied was $350 \mathrm{rpm}$ with a gap size of $15 \mathrm{~mm}$ and $5 \mathrm{~mm}$ for gap 1 and gap 2, respectively as illustrated in Figure 2. A homogeneous and well-dispersed mixture is a product obtained after the calendaring process is completed.

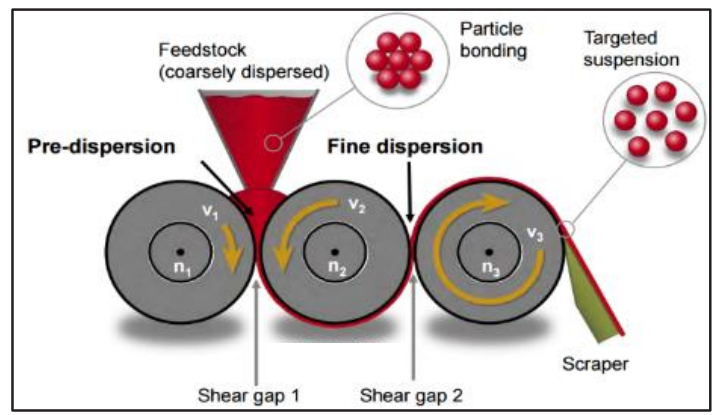

Fig.2. Three roll mill process (Source: EXAKT Advanced Technologies GmbH [13])

\subsection{Preparation of GnP/epoxy nanocomposites}

The GnPs/epoxy nanocomposites was mixed with the hardener in a dry plastic container by the ratio of 2:1 at room temperature. In order to assure the mixture was blended properly, it was stirrer using a hand electric drill mixer at a lower speed for one minute to ascertain the mixture was well blended. The mixtures were cast into the designated mould and left for 24 hours at room temperature for curing purpose. A neat epoxy grout was prepared in the same procedure without nanomaterial. Prior to testing, all specimens were polished to eliminate any impurities and surface defects. Figure 3 shows the sample preparation for GnPs/epoxy nanocomposites. 


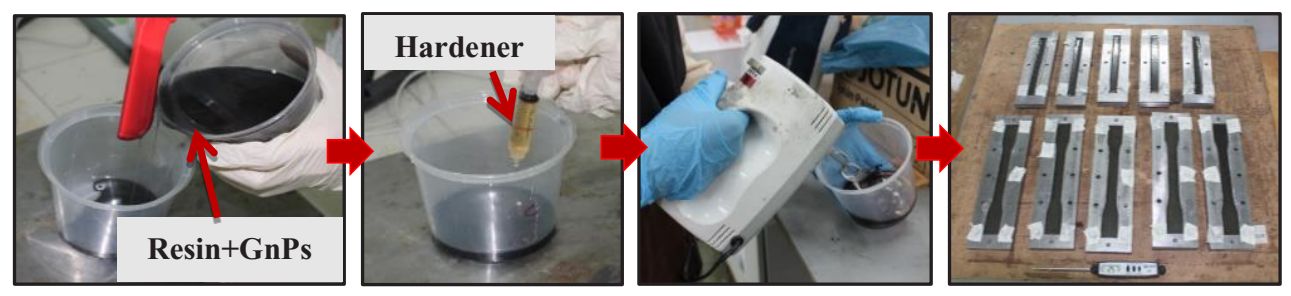

Fig.3. Sample preparation for GnPs/epoxy nanocomposites

\section{Characterization}

Mechanical tests need to be carried out to determine the properties of modified epoxy grout and to investigate the contribution of graphene as nanofiller. INSTRON 5567 Universal Testing Machine with $25 \mathrm{KN}$ of capacity is used to test the specimens until failed as shown in Figure 4. Test results reported were the average of five repetitive samples to ensure the consistent and reliable results. The tensile specimens were tested in accordance to the ASTM: D638 standard [15]. All tensile specimens were prepared in dumbbell shape with a dimension of $13.0 \mathrm{~mm} \times 3.2 \mathrm{~mm}$ (width $\mathrm{x}$ thickness). The tensile loading was applied at the constant rate $5 \mathrm{~mm} / \mathrm{min}$ until the specimen failed.

The tensile strength of the specimen can be calculated by dividing the cross-sectional area with the maximum load applied where the load can be obtained directly from the testing machine, while Young's modulus, $E$, of the grout was determined through the linear-elastic region of the stress-strain graph.

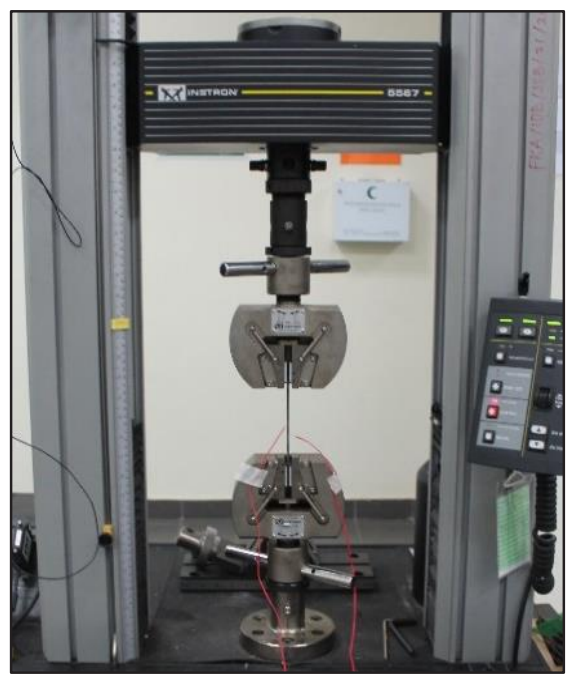

Fig.4. Tensile test using INSTRON 5567 Universal Testing Machine

\section{Results and discussion}

Tensile properties of the investigated grouts are summarized in Table 1. From the table, it can be seen the tensile strength and Young's modulus of the modified epoxy grout are found 
to increase with the inclusion of the $0.5 \mathrm{wt} \%$ graphene nanofiller. A maximum increment of $14 \%$ in the tensile strength is observed with $30.06 \mathrm{MPa}$ as compared to neat epoxy grout with 26.42 MPa, indicating significant reinforcement effect of graphene nanofiller. Besides that, it can also be noticed that graphene has improved the tensile modulus of the neat epoxy grout. A gain of $13 \%$ in the tensile modulus is observed in the modified epoxy grout from $2.21 \mathrm{GPa}$ to $2.52 \mathrm{GPa}$. As can be seen, neat epoxy grout demonstrated slightly higher strain reading at 0.0124 as compared to modified epoxy grout at 0.0117 . It showed the addition of graphene has slightly reduced the deformation of epoxy grout.

Figures 5 and 6 demonstrated the stress-strain curve and failure pattern for both grouts under tensile loading. It can be seen that both grouts exhibit linear elastic behaviour from the beginning of the testing until the specimens reach ultimate tensile strength up to failure, indicating the brittleness of the grouts. All the specimens failed due to splitting. It is observed that the failure occurred in a brittle manner without any visible deformation or necking behaviour.

Table 1. Summary of tensile test results.

\begin{tabular}{cccc}
\hline \hline Grouts & $\begin{array}{c}\text { Tensile Strength } \\
(\mathbf{M p a})\end{array}$ & $\begin{array}{c}\text { Young's Modulus } \\
(\mathbf{G P a})\end{array}$ & $\begin{array}{c}\text { Strain at Ultimate } \\
\text { Stress }(\mathbf{m m} / \mathbf{m m})\end{array}$ \\
\hline \hline Neat epoxy & $26.42 \pm 2.83$ & $2.21 \pm 0.20$ & $0.0124 \pm 0.0015$ \\
Modified epoxy & $30.06 \pm 2.76$ & $2.49 \pm 0.10$ & $0.0117 \pm 0.0013$ \\
\hline
\end{tabular}

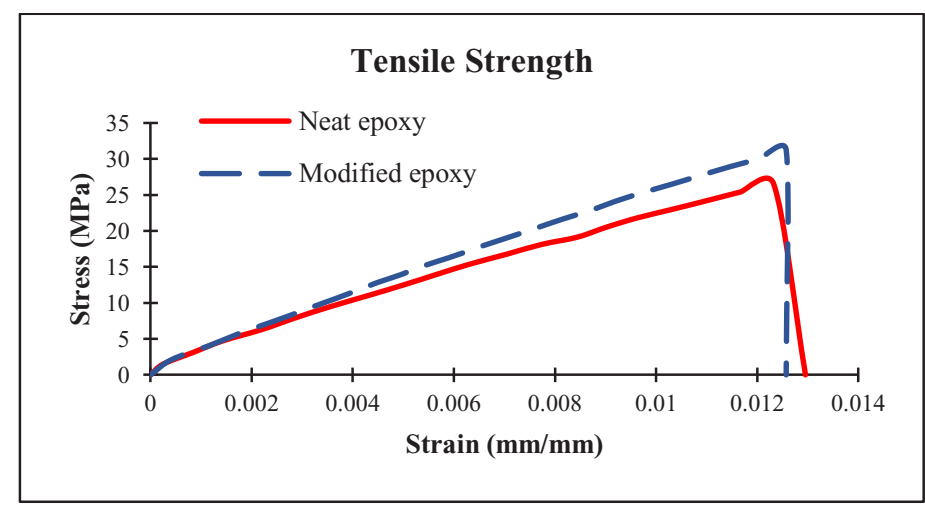

Fig.5. Tensile behaviour of epoxy grout.

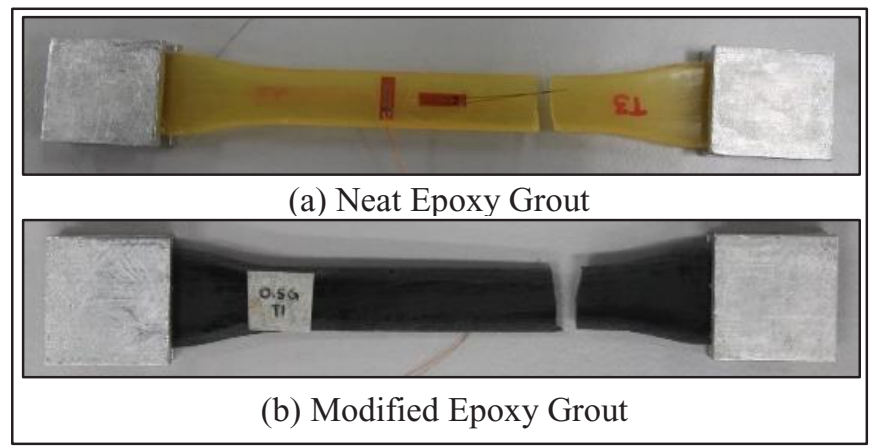

Fig.6. Tensile specimens after failure 
The requirement of high performance of epoxy grout is important since the pressurized pipe is subjected to hoop stress that causes the pipe fail in tension mode. Therefore, high tensile strength and stiffness are indispensable to provide the additional load bearing capacity and thus a better load-sharing mechanism in pipeline repair [16]. Based on the testing results, modified epoxy grout with the tensile strength of $32 \mathrm{MPa}$ is sufficient to be used in structural rehabilitation with the range of tensile strength is within $28 \mathrm{MPa}$ to $48 \mathrm{MPa}$, as suggested by Mendis [17]. The application of grout in pipeline repair with higher tensile strength is suitable to be applied at the condition with high operating pressure as it could serve as a load-sharing component instead of just transferring it from the pipeline to composite wrapping layer. Hence, it capable to provides better performance by improving the overall capacity of the repaired pipe.

\section{Conclusion}

This study investigated the influence of graphene nanoplatelets (GnPs) on the tensile properties of epoxy grout. The inclusion of low percentage of graphene in the epoxy matrix has shown a significant increase in the tensile strength and stiffness of modified epoxy grout with increments up to $14 \%$ as compared to neat epoxy grout. Thus it shows that GnPs capable to act as reinforcing agent in polymer composites. This is due to the fact that graphene nanomaterials have superior properties and already being utilized in numerous applications. Additionally, proper dispersion techniques using sonication and three-roll mill can ensure that nanomaterials capable to enhance the properties of infill material since dispersion is one of the most important factors in producing a high quality of epoxy grout. The reduction of wrapping thickness in pipeline repair can be made possible by strengthening the epoxy gout using nanomaterials, hence may reduce the overall cost of repair and time to completion of repair activity.

The study was financially supported by Universiti Teknologi Malaysia (Grant No. GUP 13H27 and 19H87), the Ministry of Education Malaysia, MOE (Grant No. FRGS 4F882), Petronas Research Sdn Bhd (Grant No. 4C132) and some of the equipment provided by the Orbiting Scientific \& Technology Sdn Bhd.

\section{References}

1. Alang, N. A., Razak, N. A., Shafie, K. A. \& Sulaiman, A. Finite Element Analysis on Burst Pressure of Steel Pipes with Corrosion Defects. in 13th International Conference on Fracture 1-10 (2013).

2. Duell, J. M., Wilson, J. M. \& Kessler, M. R. Analysis of a carbon composite overwrap pipeline repair system. Int. J. Press. Vessel. Pip. 85, 782-788 (2008).

3. Mazurkiewicz, L. et al. Experimental and numerical study of steel pipe with part-wall defect reinforced with fibre glass sleeve. Int. J. Press. Vessel. Pip. 149, 108-119 (2017).

4. Shamsuddoha, M., Islam, M. M., Aravinthan, T., Manalo, A. \& Lau, K. tak. Effectiveness of using fibre-reinforced polymer composites for underwater steel pipeline repairs. Compos. Struct. 100, 40-54 (2013). 
5. Chandra Khan, V., Balaganesan, G., Kumar Pradhan, A. \& Sivakumar, M. S. Nanofillers Reinforced Polymer Composites Wrap to Repair Corroded Steel Pipe Lines. J. Press. Vessel Technol. 139, 9 (2017).

6. Bobba, S., Leman, Z., Zainuddin, E. S. \& Sapuan, S. M. Failures Analysis of E-Glass Fibre reinforced pipes in Oil and Gas Industry: A Review. In IOP Conference Series: Materials Science and Engineering 217, 1-10 (2017).

7. Lim, K. S., Azraai, S. N. A., Noor, N. M. \& Yahaya, N. An Overview of Corroded Pipe Repair Techniques Using Composite Materials. World Acad. Sci. Eng. Technol. Int. J. Chem. Mol. Nucl. Mater. Metall. Eng. 10, 19-25 (2016).

8. Farrag, K. Selection of Pipe Repair Methods. Final Report GTI - Project Number 21087, Gas Tech. Inst.. (2013).

9. Salim, U. S. et al. Compressive, Flexural and Tensile Properties of Graphene Modified Grouts for Pipeline Rehabilitation. Malaysian J. Civ. Eng. 111, 102-111 (2016).

10. Azraai, S. N. A., Lim, K. S., Yahaya, N. \& Noor, N. M. Characterization of Mechanical Properties of Graphene-Modified Epoxy Resin for Pipeline Repair. Int. J. Chem. Mol. Nucl. Mater. Metall. Eng. 10, 15-18 (2016).

11. Atta, N. F., Galal, A. \& El-Ads, E. H. Graphene - A Platform for Sensor and Biosensor Applications. in Biosensors - Micro and Nanoscale Applications (InTech, 2015).

12. Dong, H. S. \& Qi, S. J. Realising the potential of graphene-based materials for biosurfaces - A future perspective. Biosurface and Biotribology 1, 229-248 (2015).

13. Tshai, K. Y., Khalili, P., Kong, I., Yeoh, C. H. \& Tshai, K. H. Synthesization of graphene and its incorporation into natural fiber reinforced thermosetting nanocomposite. ARPN J. Eng. Appl. Sci. 11, 121-127 (2016).

14. Exakt Advanced Technologies GmbH. Three Roll Mills. Exakt Advanced Technologies GmbH [Brochure] 1-15 (2015).

15. ASTM International. D638 - 10. Standard Test Method for Tensile Properties of Plastics. (American Society for Testing and Materials, 2010).

16. Azraai, S. N. A. Characterization of epoxy grout as infill material for pipeline composite repair system. (Universiti Teknologi Malaysia, Johor, 2017).

17. Mendis, P. Commercial Applications and Property Requirements For Epoxies In Construction. SP. ACI Spec. 89, 127-140 (1985). 